\title{
Proceeding
}

Supplementary Issue: Autumn Conferences of Sports Science. Costa Blanca Sports Science Events, 18-19 December 2020. Alicante, Spain.

\section{Inclusion in physical and sport education for special movement needs}

\author{
FRANCESCA D'ELIA \\ University of Salerno, Italy
}

\begin{abstract}
European Union countries promote an approach to social cohesion based on equity of rights. One of these fundamental rights is access to optimal health: physical activity is a key element in promoting and maintaining individual health and well-being. It is therefore necessary to guarantee full access to the right to health for all, also through a correct approach qualitative-quantitative to physical activities and sports, with particular attention to "special" populations (children, elderly, people with disabilities and more generally people who are vulnerable) which are more exposed to risk factors for health and well-being. The research activity aims to promote inclusion through physical and sports education programs able to respond to the needs for movement by "special" populations, needs that require specific and further adaptations according to the contingencies determined by the COVID-19 pandemic. The purpose is also to describe and compare the behaviours implemented and the opinions expressed, as well as the system of norms, values, beliefs to which the subjects belonging to the selected sample of participants (disabled people that practice sport activities) in the survey activity in order to define physical and sports education programs adapted to the special needs for movement.
\end{abstract}

Keywords: Adapted physical education; Disabled people; COVID-19.

\section{Cite this article as:}

D'Elia, F. (2021). Inclusion in physical and sport education for special movement needs. Journal of Human Sport and Exercise, 16(2proc), S781-S787. doi:https://doi.org/10.14198//hse.2021.16.Proc2.64

Corresponding author. University of Salerno, Italy.

E-mail: fdelia@unisa.it

Abstract submitted to: Autumn Conferences of Sports Science. Costa Blanca Sports Science Events, 18-19 December 2020. Alicante, Spain.

JOURNAL OF HUMAN SPORT \& EXERCISE ISSN 1988-5202

(c) Faculty of Education. University of Alicante

doi:10.14198/jhse.2021.16.Proc2.64 


\section{INTRODUCTION}

European Countries promote an approach to social cohesion based on equity of rights. One of these fundamental rights is access to optimal health: physical activity is a key element in promoting and maintaining individual health and well-being (Raiola, 2015a; Tiziana et al., 2016; Gaetano, 2016). Regular exercise is fundamental for staying physically and mentally fit, physical activities help to contain weight and overweight problems and play an important role in preventing and/or reducing the impact of many other health-related conditions (Altavilla et al., 2015, 2018).

In addition to the wide and multiple benefits to individual health and wellbeing, sport and physical activity have a remarkable value in the context of social inclusion and integration, they can encourage an active social inclusion because they offer opportunities for special groups (people who are vulnerable, such as disabled, migrants and people at risk of discrimination and marginalization) to fully interact and relate with other social groups. In particular, to the people with disabilities sport offer the possibility to bring out their talents and has the potential to involve everyone in an inclusive perspective.

It is necessary to guarantee full access to the right to health for all, though also a correct qualitativequantitative approach to physical activities and sports, with particular attention to special populations which are more exposed to risk factors for health and well-being. This goal is achievable through targeted socioeducational policies that can encourage people participation in regular physical activity and sport, to foster a sense of social inclusion and integration, particularly for groups that are marginalized and that often suffer from barriers, such as disabled people. Typical barriers for disabled people in approaching sport include: lack of awareness on the part of society as to how to involve them in sport and physical education programs adequately; lack of opportunities and programmes for training and competition; too few accessible facilities due to physical barriers; and limited information on access to resources (Kiuppis, 2018, DePauw et al., 2005).

The concept of inclusion underlying the present study implies go beyond the integrationist logic with which socio-educative systems tend to manage diversity, in particular with regard to disability; the lack of social inclusion does not depend on an inner deficit of the person, but on a defect in the organization of contexts and practices, which can be defined as obstacles to activities and participation.

The duo sport-disability is representative of an approach that has collected both the socio-cultural and scientific evolution of sports and physical activity in a phenomenological point of view and the vision of the disabled person in terms of bio-psycho-social functioning. The renewed awareness of the meanings attributed to the physical and sport experience and of the potential that a disabled person can express has led to the promotion and dissemination of practices aimed at highlighting the benefits of physical and sport activity and enhancing the skills of each, trying to go beyond the prejudices that over time have marked people with disabilities, limiting their lives and the possibility to practice sport and physical activities.

The most recent national and international educational guidelines tend to promote inclusive approaches, encouraging the widest participation in school and socio-educative activities by everyone. As far as disability is concerned, projects and actions aimed at inclusion are conceived and, in this regard, the socio-educational proposals centred on physical and sports experience are particularly stimulating (Altavilla et al., 2020, D'Elia et al., 2020a, Di Domenico et al., 2020, Raiola et al., 2020ab, Viscione et al., 2019).

In the sport-disability relationship, however, paths aimed at inclusion oscillate from totally "open" experiences that involve the participation of all, regardless of the individual abilities, to "exclusive" experiences that provide 
for specific adaptations and restrictions on participation as it happens in sport for the disabled that was born and developed in other contexts (such as the Paralympic one) as an exclusive area, reserved (adapted) to particular types and levels of (dis) ability. Therefore, a wide-spectrum model of inclusive sports practice emerges in the learning environment that is based on people's motivations, on the type of activity and on the level of ability and physical fitness and which have to consider individual interests and attitudes, as well as the methods of participation. There are several ways in which people with disabilities can be involved. Sometimes people with disabilities want / can participate in experiences with other disabled participants (exclusive) and other times they may choose to participate in experiences with non-disabled people (unifiedinclusive), a lot also depends on how much the activities, rules and / or the environment can be modified and adapted.

Though inclusion does not necessarily relate to people with disabilities, in this paper it will be focus the attention on the perceived level of inclusion and the participation of disabled people in sport activities in order to promote inclusion through physical and sports education programs in different learning contexts, in particular non-formal contexts (formal - i.e. schools / non-formal - i.e. federations / informal - i.e. learning in practice), to respond to the needs for movement of "special" populations needs, in particular disabled people, that require specific and further adaptations according also to the contingencies determined by the COVID19 pandemic. The solutions to deal with the problems deriving from the current health emergency have, in fact, made the implementation of inclusive activities even more complex for everybody, but disabled people have suffered greatly from the many restrictions imposed.

\section{METHODS}

To check the main issues and strengths of inclusion in sports clubs for disabled and non-disabled athletes has been identified as instrument the Index for inclusion (Boot et al., 2014), (some of) its questions have been adapted to sport contest. The Index for Inclusion generally is used in formal learning contexts such as schools, but in this case we have adapted the instrument to non-formal environments such as sports clubs which offer opportunities for participation also for disabled people. The purpose of using this tool is to carry out self-analysis of the degree of inclusiveness of the sport club contexts and make the necessary changes to increase the inclusion of all members who belong to them.

The index consists of 5 questionnaires that aim to bring out useful elements for creating inclusive cultures and policies and developing inclusive practices. For the purposes of this preliminary study, only one of the 5 questionnaires was adapted, in particular the questionnaire number 2, the structure of the questions remained unchanged, the terms were modified by adapting the questions to the context of sporting practice.

A sample of 62 disabled athletes (65\% male - 35\% female), attending sport clubs of south Italy took part in the study with an average age of 22,5 . The adapted Index questionnaire was prepared with Google Forms and disseminated by e-mail.

The questionnaire was composed by 24 statements divided into three sections: policies, cultures and practices; in each section there are statements that describe the sports club to which they belong, for each statement the athletes had to describe the level of agreement (fully agree, agree, partially agree, disagree). 


\section{RESULTS}

To analyse the answers (Table 1) descriptive statistics were used and the variables have been expressed as a percentage.

- Below $60 \%$ represents the aspects on which there is an urgent need for intervention;

- Between $60 \%$ and $70 \%$ represents the aspects on which to intervene preventively;

- Between $70 \%$ and $80 \%$ represents the aspects that do not require special precautions;

- From $80 \%$ it already represents a good percentage of inclusion on which, however, there is always room for improvement.

Table 1. Index questionnaire no. 2 adapted to sport context.

\section{Cultures:}

1) Everyone feels welcome in the team $-75.2 \%$

2) The players help each other $-75.8 \%$

3) The coaches collaborate with each other $-71.3 \%$

4) Coaches and players treat each other with respect $-76.8 \%$

5) Parents are involved in the life of the team $-56 \%$

6) The coaches and the president of the company collaborate positively $-75 \%$

7) Coaches do not favour a group of players over the other $-54.2 \%$

8) The coaches help the players to give their best $-83 \%$

9) The coaches think that all players are equally important $-54.5 \%$

Policies:

10) The company facilitates the registration of people with disabilities - $51 \%$

11) In the first period of insertion into the company you are helped to settle $-70.5 \%$

12) Coaches like to work in all their team groups $-71.7 \%$

13) The coaches face the behavioural problems of the players in order to avoid demotivation and abandonment $-72.1 \%$

14) The coaches are committed to ensuring that the gym becomes a place where people are happy to come - $82 \%$

15) Everything possible is done to prevent and combat bullying - $80,2 \%$

Practices:

16) The coaches facilitate the understanding of the exercises for all - $81.3 \%$

17) Players are taught to appreciate people with a background other than their own $-82.4 \%$

18) Players usually know what will be trained in the next training - $46 \%$

19) Coaches expect players to help each other - $87 \%$

20) In most of the training sessions, athletes and coaches behave with respect to each other $80 \%$

21) Coaches help anyone who experiences difficulties in following the training $81,4 \%$

22) The second coach does his utmost to help all athletes in difficulty $78 \%$

23) The exercises to be done at home help learning and are clearly explained $65.3 \%$

24) Outside of the training sessions, activities are proposed that affect all athletes $64.2 \%$

Table 2. Athletes' perceived inclusion.

\begin{tabular}{lc}
\hline Dimension & Average of perceived inclusion \\
\hline Cultures & $69 \%$ \\
Policies & $71.25 \%$ \\
Practices & $73.9 \%$ \\
\hline
\end{tabular}

S784 | 2021| Proc2 | VOLUME 16

(C) 2021 University of Alicante 


\section{DISCUSSION}

In this preliminary phase the results show a good degree of perceived inclusion (Table 2) by disabled athletes in sport clubs. From the answers emerges the desire by the athletes to be involved during planning phase of activities and architectural barriers also emerge.

Central importance is attributed to the processes and mechanisms of inclusion that operate within sporting environments. Supporting dialogue between disabled people, family, policy makers and sport organisers promotes social inclusion, giving the opportunity to build healthy lifestyles, cooperate to achieve common goals and to benefit through the coordination of sport organizations and educational institutions' activities in order to promote greater participation in sport.

More extensive interaction between sport and education is needed to promote the sharing of good practice (Pisapia, 2018, Boccia et al., 2019, D'Isanto, 2020, Latorella, 2020, Raiola, 2015b) and help to:

- Improve the quality of physical education programmes and enhance teachers' and coaches' competences and skill levels about inclusion;

- Provide young high-level athletes with quality education alongside their sport training, helping them to both study and compete;

- Respond to sport education challenges;

- Modernise coaches training about inclusion and adapted sport and physical activities.

\section{CONCLUSION}

The focus on the development of the movement and physical skills in the life of the disabled person has greatly changed. There is awareness of the positive value of physical and sport activity and the benefits that can be found in all areas of functioning of the person (Raiola, 2013).

Adequate physical and sports education programmes in each learning context (formal, non-formal and informal):

- Satisfy the needs for autonomy, competence and relationship of the person;

- Improve attention and participation in activities;

- Enhance the ability to finalize a behaviour to a task to be carried out;

- Help to respond correctly to requests;

- They favour body and movement control, improving posture;

- Channel excess energy by improving behaviour and keeping inappropriate behaviour under control;

- Balance and regulate the nutrition / energy expenditure ratio.

The list cannot be exhaustive, the benefits are many to the extent that these activities improve the lives of the people who practice them. To implement their effectiveness, it is necessary to adapt the proposals for physical and sports education, so as to fully enhance individual potential.

Through this preliminary study it has been possible to quantify inclusion in sport and highlight both the main problems related to it but also the strengths already achieved and consolidated.

The next steps are to extend the survey to a representative sample of athletes, to integrate the qualitative method by focus group with athletes (D'Elia, 2020) and to define physical and sports education programmes adapted to the special needs for movement (D'Elia et al., 2020b) of athletes (disabled and no disabled). 


\section{REFERENCES}

Altavilla, G., D'Isanto, T., \& D'Elia, F. (2020). The educational value of rules in basketball. Journal of Human Sport and Exercise, 15(4proc), S1195-S1203. https://doi.org/10.14198/ihse.2020.15.Proc4.21

Altavilla, G., D'Elia, F., Raiola, G. (2018) A breif review of the effects of physical activity in subjects with cardiovascular disease: An interpretative key. Sport Mont, 16 (3), pp. 103-106. https://doi.org/10.26773/smj.181018

Altavilla, G., Furino, F., Marika, D.P., Raiola, G. (2015) Physical skills, sport learning and socio-affective education [Fizičke vještine, sportsko učenje I društveno-afektivno obrazovanje], Sport Science, 8, pp. 44-46.

Boccia, S., Izzo, R., D'elia, F., Fattore, S. (2019) A wheelchair by the overboard model: A technological instrument for disabled basketball players, Journal of Human Sport and Exercise, 14 (Proc4), pp. S1080-S1086. https://doi.org/10.14198/ihse.2019.14.Proc4.71

Booth T., Ainscow M. (2014). Nuovo Index per l'inclusione - Percorsi di apprendimento e partecipazione a scuola (edizione italiana a cura di Fabio Dovigo), Carocci Faber.

DePauw, K. P., Gavron, S. J. (2005). Disability and Sport. Champaign, IL: Human Kinetics. https://doi.org/10.5040/9781492596226

D'Elia, F., Sgrò, F., D'isanto, t. (2020a) The educational value of the rules in volleyball, Journal of Human Sport and Exercise, 15, pp. S628-S633. https://doi.org/10.14198/ihse.2020.15.Proc3.15

D'Elia, F., Tortella, P., Sannicandro, I., \& D'Isanto, T. (2020). Design and teaching of physical education for children and youth. Journal of Human Sport and Exercise, 15(4proc), S1527-S1533. https://doi.org/10.14198/ihse.2020.15.Proc4.48

D'Elia, F. (2020). Teachers' perspectives about contents and learning aim of physical education in Italian primary school. Journal of Human Sport and Exercise, 15(2proc), S279-S288. https://doi.org/10.14198/ihse.2020.15.Proc2.19

D'isanto, T. (2020) Sports skills in sitting volleyball between disabled and non-disabled people, Journal of Physical Education and Sport, 20 (3), art. no. 194, pp. 1408-1414.

Di Domenico, F., Sannicandro, I., Altavilla, G. (2020) The educational value of the rules in five-a-side football, Journal of Human Sport and Exercise, 15, pp. S645-S655. https://doi.org/10.14198/ihse.2020.15.Proc3.17

Gaetano, A. (2016) Relationship between physical inactivity and effects on individual health status, Journal of Physical Education and Sport, 16, pp. 1069-1074.

Kiuppis, Florian (2018) Inclusion in sport: disability and participation, Sport in Society, 21:1, 4-21. https://doi.org/10.1080/17430437.2016.1225882

Latorella, V., Di domenico, F., Altavilla, G. (2020) Neuromuscular adaptations to a motor skills training program for adults with intellectual disabilities, Journal of Human Sport and Exercise, 15 (Proc3), art. no. S676. https://doi.org/10.14198/ihse.2020.15.Proc3.20

Pisapia, F., D'Isanto, T. (2018) Inclusive methods of adaptive training in sprints: A theoretical preliminary study, Journal of Physical Education and Sport, 18, art. no. 316, pp. 2101-2105.

Raiola, G., Invernizzi, P.L., Scurati, R., \& Fattore, S. (2020a). The educational value of the rules in handball. Journal of Human Sport and Exercise, 15(4proc), S1214-S1223. https://doi.org/10.14198/ihse.2020.15.Proc4.23

Raiola, G., Esposito, G., Sgrò, F. (2020b) The formative value of soccer rules, Journal of Human Sport and Exercise, 15, pp. S656-S663. https://doi.org/10.14198//hse.2020.15.Proc3.18

Raiola, G. (2013) Body knowledge and motor skills, Knowledge Cultures, 1 (6), pp. 64-72. 
Raiola, G. (2015a) Sport skills and mental health, Journal of Human Sport and Exercise, 10 (Specialissue), pp. S369-S376. https://doi.org/10.14198//hse.2015.10.Proc1.27

Raiola, G. (2015b) Inclusion in sport dance and self perception, Sport Science, 8, pp. 99-102.

Tiziana, D., Antonetta, M., Gaetano, A. (2017) Health and physical activity [Zdravlje i tjelesna aktivnost] Sport Science, 10 (1), pp. 100-105.

Viscione, I., Invernizzi, P.L., Raiola, G. (2019) Physical education in secondary higher school, Journal of $\begin{array}{llll}\text { Human Sport and Exercise, } 14 \text { (Proc4), pp. S706-S712. } & \text {. }\end{array}$ https://doi.org/10.14198//hse.2019.14.Proc4.31 